\title{
Elitist Teaching Learning Opposition based Algorithm for Global Optimization
}

\author{
Anguluri Rajasekhar, Rapol Rani, Kolli Ramya \\ Department of Electrical and Electronics Engineering \\ National Institute of Technology-Warangal \\ Andhra Pradesh, INDIA \\ Email: rajasekhar.anguluri@ieee.org,rani.rapol@ieee.org, \\ ramyakolli@ieee.org
}

\author{
Ajith Abraham, Senior Member IEEE \\ Faculty of Computer Science and Electrical Engineering \\ VSB-Technical University of Ostrava, Czech Republic \\ Machine Intelligence Research Labs (MIR Labs), USA \\ Email: ajith.abraham@ieee.org
}

\begin{abstract}
In this paper, a new variant of Teaching-Learning based Optimization (TLBO), termed as Elitist Teaching-Learning Opposition based (ETLOBA) Algorithm has been proposed for numerical function optimization. The proposed method is empowered with two mechanisms to reach the accurate global optimum with less time complexity. One of them is elitism, which strengthens the capability of optimization method by retaining the best solution obtained so far, on the other hand Opposition method helps in ameliorating the capability of searching. As ETLOBA had an advantage of both Elitism and Opposition based learning, hence it tries to obtain optimum solutions with guaranteed convergence. The proposed method has been tested on several benchmark functions and the results obtained by ETLOBA are been compared with new state-of-art optimization methods like ABC, HS etc., shows the superiority of the proposed approach in solving continuous optimization problems.
\end{abstract}

Keywords-oppostion learning; global optimization; elitism; artificial bee colony;

\section{INTRODUCTION}

Teaching-Learning-Based Optimization (TLBO) is one of the new meta-heuristic optimization algorithm proposed by Rao et al. [1] for continuous non-linear large-scale optimization. TLBO method relies on the philosophy of teaching and learning i.e., optimization procedure is structured based on the effect of the influence of a teacher on the output of learners in a class. In a short time of its evolution it has been applied to various practical optimization problems, few of the challenging real world applications include mechanical design, design of planar steel frames, welding [2-4] and so on.

Though Rao et al. [1] reported that TLBO has outperformed various state-of-art methods when applied to continuous function optimization, but there are few inherent drawbacks, which restrict the algorithm to perform well only on few benchmarks and functions having less dimensions. One of the major disadvantages of TLBO is the convergence rate, and it gets even worse when dealt with higher dimension problems. The performance gets even worse while solving the functions like Rosenbrock and hence some mechanism has to be incorporated to achieve the highest performance.

To overcome the drawbacks and to enjoy the results of TLBO we proposed a new Elitist-Teaching-Learning Opposition based Algorithm. Elitism is a concept utilized most in the evolutionary algorithms where during every generation the worst solutions are replace by elite solutions. This helps the algorithm in always retaining the values closer to the optimum and discarding the worst values obtained so far. While on the other hand Opposition helps in increasing the exploration capability by making algorithm to search in the diverse areas and hence this opposition takes care about the global exploration.

The remainder of paper is structured as follows. In Section II we discuss about basic version of TLBO. The proposed ETLOBA and the modifications made are briefed in Section III. Section IV provides detailed comparison of ETLOBA with remaining state of art optimization methods on various benchmark functions considered. Finally we put forth some conclusions and future scope in Section V.

\section{TEACHING-LEARNING-BASED OPTIMIZATION}

Like many other meta-heuristics, TLBO also draws its inspiration from the teaching-learning process in a class of teacher and the learners. Teacher tries to reach best harmony on the output of learners in a class, which can be obtained through their grades considered as the output. Output is appraised by means of exam conducted by the teacher.

The TLBO is explained here is same to that of work carried out by Rao et al. [1]. Supposing two different teachers, $T_{1}$ and $\mathrm{T}_{2}$, are teaching a subject with same content to the same merit level learners in two different classes. Distribution of marks obtained by the learners of two different classes evaluated by the teachers are depicted Figure1. A normal distribution is assumed for the obtained grades after taking an exam by the teachers.

It is evident from Figure 1 that the teacher who deals with the learners in the class 2 is performing better than the teacher dealing with learners of class 1 . This can be interpreted via the mean of the grades, $M_{2}$, obtained by the learners in the class 2 represents better results than $M_{l}$. Hence from the Figure1 it can be concluded that a good teacher produces a better mean for the results of the learners. Learners also learn from interaction between themselves, which also helps in their results. 


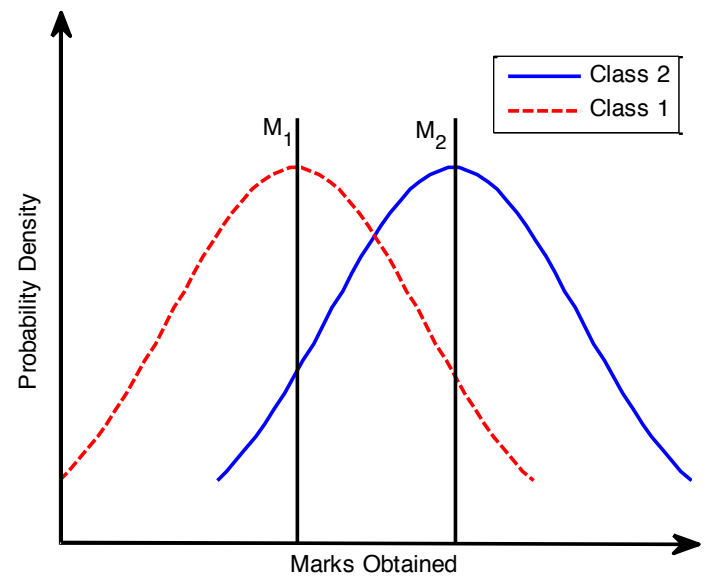

Fig 1. Distribution of Marks obtained by learners thought by two teachers

Teacher is considered as the most knowledgeable person in the society and hence every teacher tries to disseminate knowledge among the class of learners to increase the knowledge level of the class and help learners to get good marks. However, in practice a teacher can only move the mean of a class up to some extent depending on the capability of the class [1].

Although the teacher makes a maximum effort in teaching his/her learners, learners will gain knowledge according to the quality of teaching delivered by a teacher and the quality of learners present in class. There are other means in which learners can also gain knowledge by discussing, discovering and interacting with the other learners [1].

In this method the population (individuals) is considered as a class of learners and different dimensions related to each individual are analogous to different subjects. Learners' result is the fitness value and teacher being considered as the best value of iteration. TLBO consists of two phases i.e., Teacher phase and Learner phase. In Teacher phase, all the learners are updated based upon the teacher; on the other hand in Learner phase, all the learners are updated based on the other learner. Once the two phases are completed consequently, the teacher is also updated before progressing into next iteration. Like other stochastic based methods TLBO also progress iteratively towards the optimal solution.

\section{A. Teacher Phase}

At any $i_{t h}$ iteration, let $M_{i}$ be the mean and $T_{i}$ be the teacher. Based on the skill and experience teacher $T_{i}$ will try to move mean $M_{i}$ towards its own level, and now the new mean corresponding to $T_{i}$ will be designated as $M_{\text {new }}$. An adaptive heuristic is used to updated the solution and is done according to the difference between the existing and the new mean given by

$$
\text { Difference_Mean }{ }_{i}=\operatorname{rand}_{i}\left(M_{\text {new }}-T_{F} M_{i}\right)
$$

where $T_{F}$ is termed as teaching factor, which decides whether the value of mean is to be changed or not. The value of $T_{F}$ can be either 1 or 2 , which is decided randomly with equal probability and rand $_{i}$ is a random number in the range $[0,1]$. The value of $\mathrm{T}_{\mathrm{F}}$ plays very vital role in updating the teacher and learner's position based on the global minimum. The value of teaching factor $\left(\mathrm{T}_{\mathrm{F}}\right)$ is defined instantly in algorithm based on the learner's position. Based on the Difference_Mean $n_{i}$ the existing solution is updated in teacher phase according to the following expression.

$$
X^{\text {new }, i}=X^{\text {old, },}+\text { Difference_Mean } n_{i}
$$

where $X^{\text {new }, i}$ and $X^{\text {old, } i}$ are the new and existing solutions corresponding to iteration $i$.

\section{B. Learner Phase}

In this phase learners increase their knowledge mainly by two different means: one through input from the teacher and other through interaction between their fraternities. In the course of time a learner may interact randomly with other learners with the help of communications, discussions, etc. If a leaner interacts with other learner who has more knowledge than him or her he tries to learn new things and tries to increase his knowledge. For a class of $P_{n}$ learners, learner modification is carried via a pseudo code provided.

\section{Pseudo code of Learner Phase}

For $i=1$ to $P_{n}$

Randomly select another learner $X_{j}$, such that $i \neq j$

$$
\begin{aligned}
\text { IF } f\left(X_{i}\right)<f\left(X_{j}\right) \\
X^{\text {new }, i}=X^{\text {old }, i}+\operatorname{rand}_{i}\left(X_{i}-X_{j}\right)
\end{aligned}
$$

ELSE

$$
X^{\text {new }, i}=X^{\text {old }, i}+\operatorname{rand}_{i}\left(X_{j}-X_{i}\right)
$$

\section{End IF}

\section{End FOR}

Accept $X^{\text {new }}$ if it gives a better function value.

After one successful completion of Teacher and Lerner phase, algorithm is made to update teacher value before the start of next iteration. The same pseudo code is applicable for maximization problem also. The only difference for maximization is that, when two learners are considered, the value of a leaner is updated based on the learner providing maximum fitness value

\section{Elitist TeACHING-LEARNING-OPPOSITION-BASED ALGORITHM}

\section{A. Elitism}

Elitism is a mechanism to preserve the best individuals from generation to generation. It had been widely used in the field of evolutionary algorithms to obtain the solution with less computational effort [5]. In the TLBO algorithm after replacing the existing worst solutions with elite solutions at the end of learner phase, if the duplicate solutions exist then care is taken modify the duplicate solutions in order to avoid trapping in the local optima. There are many strategies to modify the obtained duplicate solutions and in this method we had modified duplicated solutions by mutation on randomly selected dimensions of the duplicate solutions before executing the next generation. Now after every learner phase 
best solutions are retained and the teacher is being updated with the best solution obtained so far. Once the elitism has been introduced now the algorithm has to be further strengthened via increasing the global exploration capabilities which is done by using Opposition based learning rule.

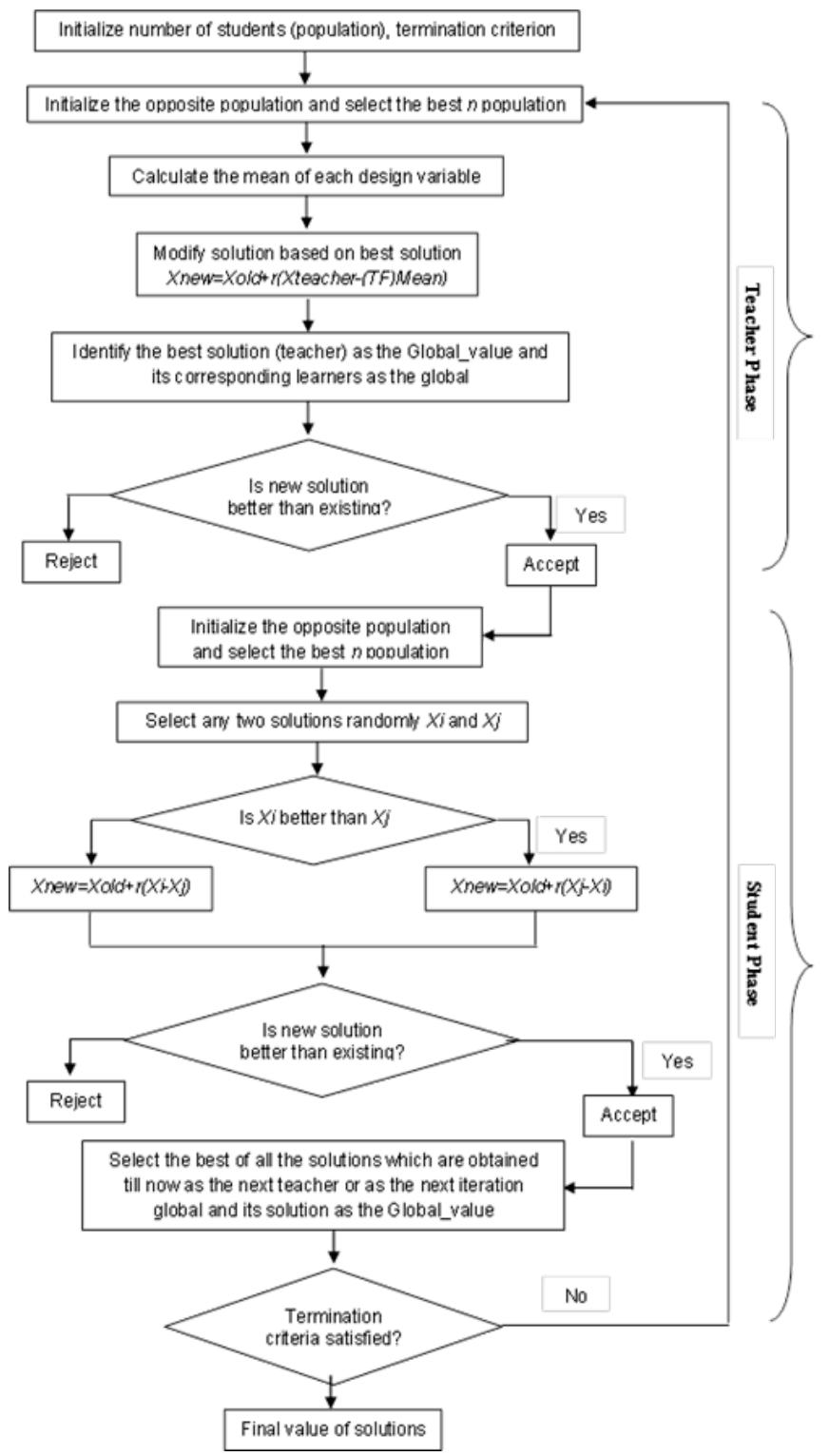

Fig 2 Flowchart of ETLOBA

\section{B. Opposition Based Optimization}

Let $P=\left\{x_{1}, x_{2}, \ldots, x_{D}\right\}$ be a point in $D$-dimensional space, where $x_{1}, x_{2}, \ldots, x_{D} \in R$ and $x_{i} \in\left[a_{i}, b_{i}\right] \quad \forall i \in\{1,2, \ldots, D\}$. Now $P^{\prime}=\left\{x_{1}^{\prime}, x_{2}^{\prime}, \ldots, x_{D}^{\prime}\right\} \quad$ i.e., opposite point $P^{\prime}=\left\{x_{1}^{\prime}, x_{2}^{\prime}, \ldots, x_{D}^{\prime}\right\}$ is defined as $[7,8]$

$$
x_{i}^{\prime}=a_{i}+b_{i}-x_{i}
$$

Now, with above definition of opposite point the opposition-based optimization can be formulated as follows.
Assuming $f(\cdot)$ is fitness function via which candidate fitness is measured and according to the above given definitions of $P$ and $P^{\prime}$ if $f\left(P^{\prime}\right) \geq f(P)$ then the point $P$ can be replaced with $P^{\prime}$; hence, the point and its opposite point are evaluated simultaneously in order to go with the fitter one.

The step by step execution of ETLOBA involving elitism and opposition based learning is depicted in Figure 2.

\section{EXPERIMENTS AND RESULTS OVER BENCHMARK FUNCTIONS}

In this section we validated the performance of proposed ETLOBA method over a test suite of 5-well known benchmark functions of different dimensions (D) ranging from 10 to 100. The mathematical representation and range of search $(\mathrm{S})$ are recorded in Table I. All the functions have theoretical optima of 0 and to achieve this we had considered a termination criterion of 2000 functional evaluations (NFEs) for ETLOBA. An exception has been provided for function $\mathrm{f}_{5}$ (Rosenbrock), where 50 learners and total of 50,000 functional evaluations are considered. The obtained values of test functions for 100 independent runs are recorded in Table II.

Table I. Description of Benchmark Functions

\begin{tabular}{|l|l|c|}
\hline Function & Mathematical Representation & S \\
\hline Sphere & $f_{1}(\vec{x})=\sum_{i=1}^{D} x_{i}^{2}$ & $(-100,100)$ \\
\hline Rastrigin & $f_{2}(\vec{x})=\sum_{i=1}^{D-1}\left[x_{i}^{2}-10 \cos \left(2 \pi x_{i}\right)+10\right]$ & $(-5.12,5.12)$ \\
\hline Ackley & $f_{3}(\vec{x})=-20 \exp \left(-0.2 \sqrt{\frac{1}{D} \sum_{i=1}^{D} x_{i}^{2}}\right)-$ & $(-32,32)$ \\
\hline Grienwank & $-\exp \left(\frac{1}{D} \sum_{i=1}^{D} \cos \left(2 \pi x_{i}\right)\right)+20+e$ & 1 \\
\hline Rosenbrock & $f_{5}(\vec{x})=\sum_{i=1}^{D}\left[1000 \sum_{i=1}^{D} x_{i}^{2}-\prod \cos \left(\frac{x_{i}}{\sqrt{i}}\right)+1\right.$ & $(-600,600)$ \\
\hline
\end{tabular}

A. Algorithmic Parameters and Competitor Algorithms Used

ETLOBA also enjoys the advantage of having less number of parameters similar to TLBO. The only parameter to be decided is the number of learners and in this case for both TLBO and ETLOBA we had chosen it as $10\left(P_{n}=10\right)$. The proposed ETLOBA along with TLBO is also compared with other state-of-art methods, which include Harmonic Search (HS), Improved Bees Algorithm (IBA), and Artificial Bee Colony (ABC).

\section{B. Discussion on Results}

At first we made a comparison of results obtained with that of ETLOBA to TLBO in terms of, best fitness solution obtained in 100 runs, Mean value, and standard deviation (STD). These values are recorded in Table II and the best 
values are marked in bold. For functions $F_{1}$ and $F_{5}$ ETLOBA performed exceptionally well in terms of all three metrics considered. As the results obtained for functions $\mathrm{F}_{2}-\mathrm{F}_{4}$ using both the algorithms met theoretical optima, we had analyzed the performance based on convergence characteristics (for highest dimension 100), which are depicted in Fig 3-7. From the Table I and figures (Figures 3-7) it is evident that ETLOBA had outperformed TLBOA in terms of quality of solution and also in convergence rate. To further validate the performance of ETLOBA method over other few successful meta-heuristics proposed in previous years we had compared the results of ETLOBA with few of the potential methods like HS, IBA, ABC [6] and also with original TLBO [1]. From Table III it was very clear that ETLOBA had outperformed rest of methods for a total four functions out of 5 considered. Though ETLOBA had got better result for function $\mathrm{F}_{5}$ when compared with TLBO (ref Table II, III) but ABC performed exceptionally well than ELOBA.

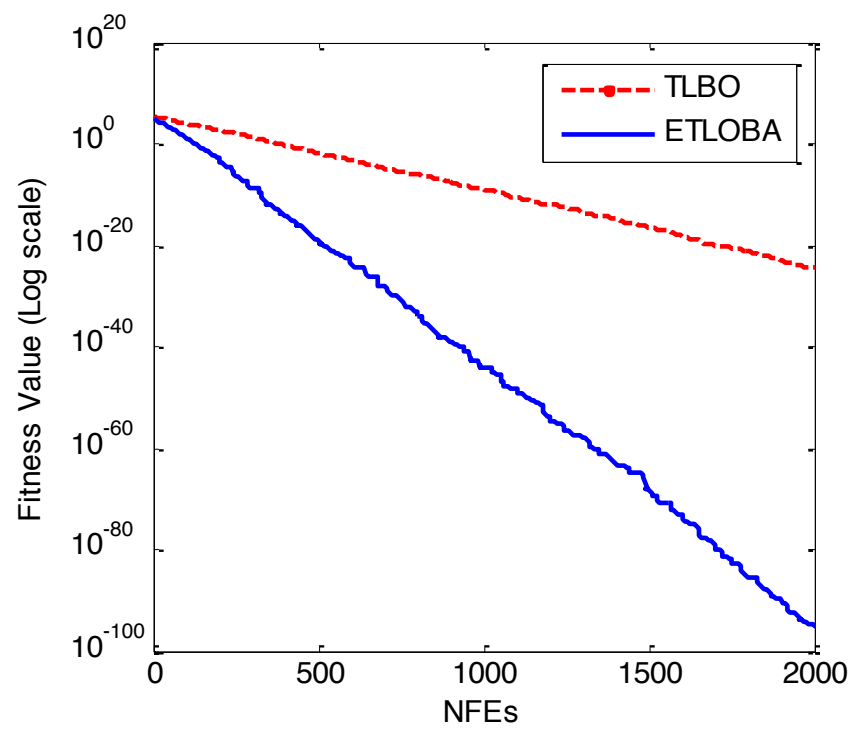

Fig. 3. Convergence of ETLOBA and TLBO for $F_{1}$ function (100-D)

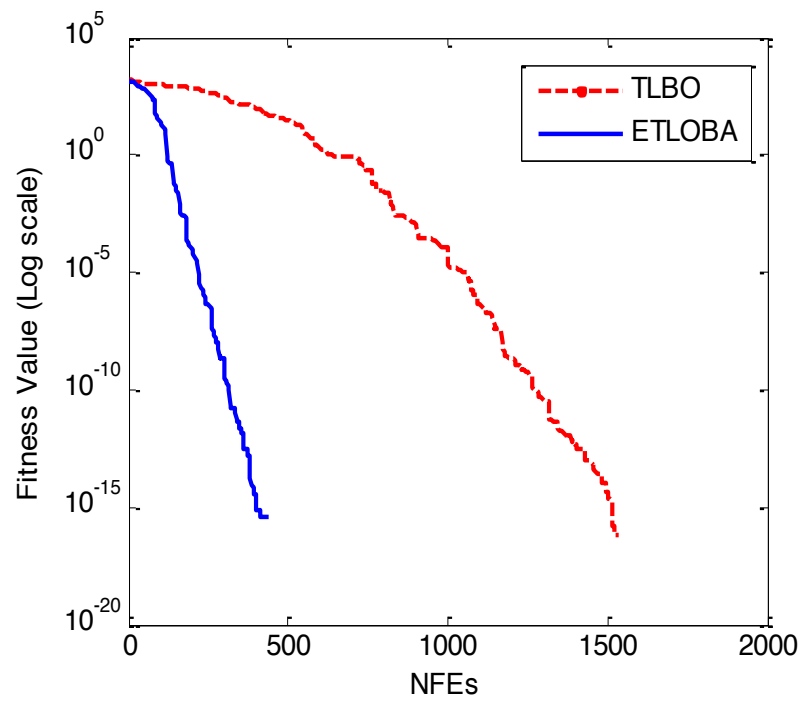

Fig. 4. Convergence of ETLOBA and TLBO for $F_{2}$ function (100-D)

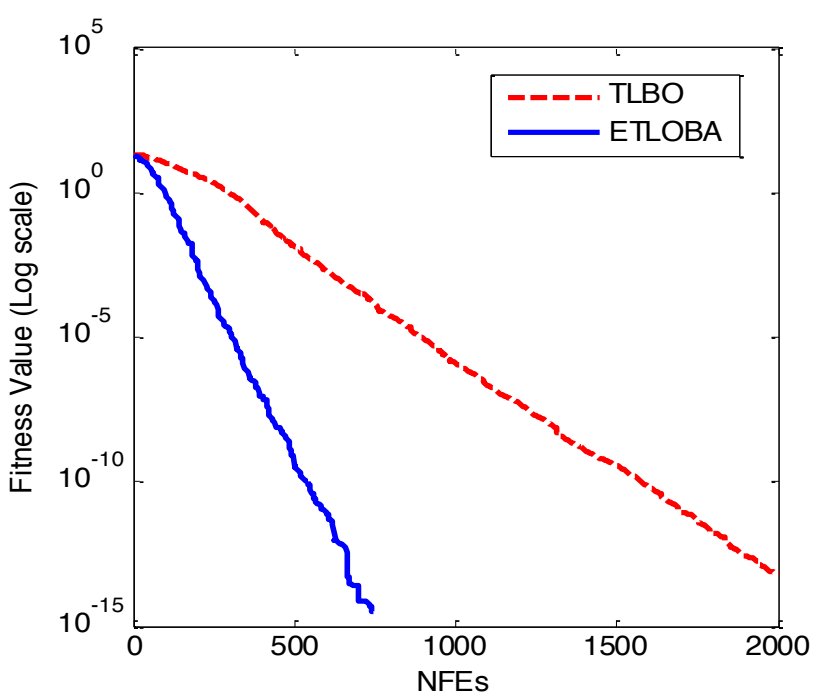

Fig. 5. Convergence of ETLOBA and TLBO for $F_{3}$ function (100-D)

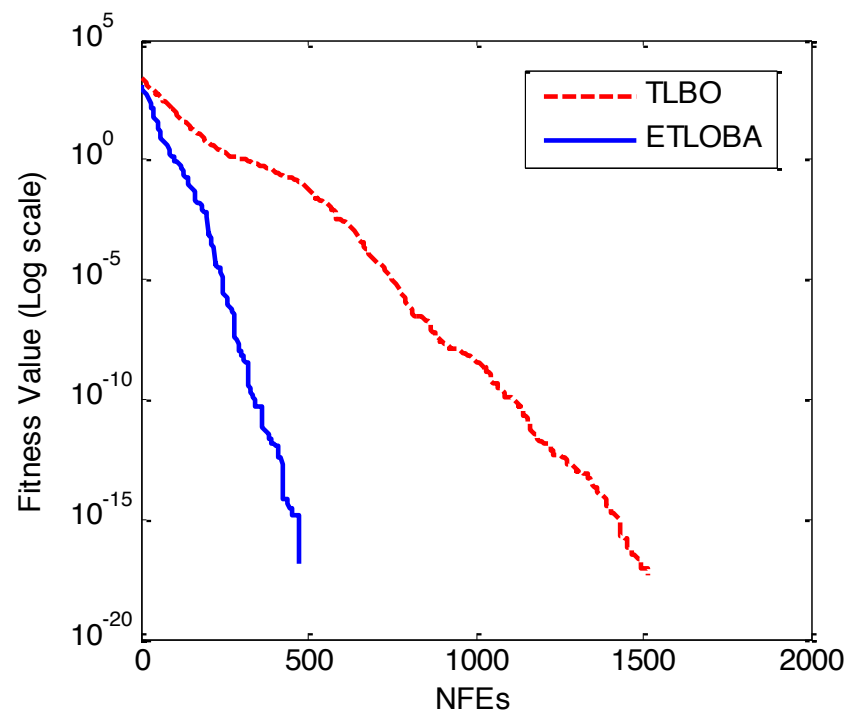

Fig. 6. Convergence of ETLOBA and TLBO for $F_{4}$ function (100-D) 
Table II. Comparison of ABC and L-ABC in terms of Error, Standard Deviation and Fitness on traditional benchmarks

\begin{tabular}{|c|c|c|c|c|c|c|c|}
\hline \multirow{2}{*}{ Function } & \multirow{2}{*}{$\begin{array}{c}\text { Dimensions } \\
\text { (D) }\end{array}$} & \multicolumn{2}{|c|}{ Best Fitness Value } & \multicolumn{2}{|c|}{ Mean } & \multicolumn{2}{|c|}{ Standard Deviation } \\
\hline & & TLBO & ETLOBO & TLBO & ETLOBO & TLBO & ETLOBO \\
\hline \multirow{4}{*}{$f_{l}$} & 10 & $2.25 \mathrm{E}-32$ & $5.50 E-169$ & $5.47 \mathrm{E}-26$ & 9.90E-106 & $1.93 \mathrm{E}-025$ & $4.95 \mathrm{E}-105$ \\
\hline & 30 & $6.32 \mathrm{E}-35$ & $3.60 \mathrm{E}-165$ & $6.04 \mathrm{E}-27$ & $2.35 E-099$ & $1.54 \mathrm{E}-026$ & 1.18E-098 \\
\hline & 50 & $4.53 \mathrm{E}-31$ & 2.31E-177 & $2.86 \mathrm{E}-25$ & $9.72 \mathrm{E}-102$ & $9.51 \mathrm{E}-025$ & 3.44E-101 \\
\hline & 100 & $1.61 \mathrm{E}-32$ & $1.76 \mathrm{E}-175$ & $3.06 \mathrm{E}-25$ & $7.07 E-103$ & $7.22 \mathrm{E}-025$ & $2.60 \mathrm{E}-102$ \\
\hline \multirow{4}{*}{$f_{2}$} & 10 & $0.00 \mathrm{E}+00$ & $0.00 \mathrm{E}+00$ & $0.00 \mathrm{E}+00$ & $0.00 \mathrm{E}+00$ & $0.00 \mathrm{E}+00$ & $0.00 \mathrm{E}+00$ \\
\hline & 30 & $0.00 \mathrm{E}+00$ & $0.00 \mathrm{E}+00$ & $0.00 \mathrm{E}+00$ & $0.00 \mathrm{E}+00$ & $0.00 \mathrm{E}+00$ & $0.00 \mathrm{E}+00$ \\
\hline & 50 & $0.00 \mathrm{E}+00$ & $0.00 \mathrm{E}+00$ & $0.00 \mathrm{E}+00$ & $0.00 \mathrm{E}+00$ & $0.00 \mathrm{E}+00$ & $0.00 \mathrm{E}+00$ \\
\hline & 100 & $0.00 \mathrm{E}+00$ & $0.00 \mathrm{E}+00$ & $0.00 \mathrm{E}+00$ & $0.00 \mathrm{E}+00$ & $0.00 \mathrm{E}+00$ & $0.00 \mathrm{E}+00$ \\
\hline \multirow{4}{*}{$f_{3}$} & 10 & $3.55 \mathrm{E}-15$ & $0.00 E+00$ & $3.07 \mathrm{e}-14$ & $0.00 E+00$ & $6.84 \mathrm{e}-14$ & $0.00 \mathrm{E}+00$ \\
\hline & 30 & $3.55 \mathrm{E}-15$ & $0.00 E+00$ & $7.99 \mathrm{e}-14$ & $0.00 \mathrm{E}+00$ & $2.46 \mathrm{e}-13$ & $0.00 \mathrm{E}+00$ \\
\hline & 50 & $3.55 \mathrm{E}-15$ & $0.00 E+00$ & $4.71 \mathrm{e}-14$ & $0.00 \mathrm{E}+00$ & $9.10 \mathrm{e}-14$ & $0.00 \mathrm{E}+00$ \\
\hline & 100 & $3.55 \mathrm{E}-15$ & $0.00 E+00$ & $6.60 \mathrm{e}-14$ & $0.00 \mathrm{E}+00$ & $1.95 \mathrm{e}-13$ & $0.00 E+00$ \\
\hline \multirow{4}{*}{$f_{4}$} & 10 & $0.00 \mathrm{E}+00$ & $0.00 \mathrm{E}+00$ & $0.00 \mathrm{E}+00$ & $0.00 \mathrm{E}+00$ & $0.00 \mathrm{E}+00$ & $0.00 \mathrm{E}+00$ \\
\hline & 30 & $0.00 \mathrm{E}+00$ & $0.00 \mathrm{E}+00$ & $0.00 \mathrm{E}+00$ & $0.00 \mathrm{E}+00$ & $0.00 \mathrm{E}+00$ & $0.00 \mathrm{E}+00$ \\
\hline & 50 & $0.00 \mathrm{E}+00$ & $0.00 \mathrm{E}+00$ & $0.00 \mathrm{E}+00$ & $0.00 \mathrm{E}+00$ & $0.00 \mathrm{E}+00$ & $0.00 \mathrm{E}+00$ \\
\hline & 100 & $0.00 \mathrm{E}+00$ & $0.00 \mathrm{E}+00$ & $0.00 \mathrm{E}+00$ & $0.00 \mathrm{E}+00$ & $0.00 \mathrm{E}+00$ & $0.00 \mathrm{E}+00$ \\
\hline \multirow{4}{*}{$f_{5}$} & 10 & $3.84 \mathrm{E}+03$ & $8.92 \mathrm{E}+00$ & $4.31 \mathrm{E}+04$ & $8.97 \mathrm{E}+01$ & $3.80 \mathrm{E}+04$ & 2.13E-02 \\
\hline & 30 & $6.67 \mathrm{E}+04$ & $2.89 \mathrm{E}+01$ & $3.43 \mathrm{E}+05$ & $2.90 \mathrm{E}+01$ & $2.24 \mathrm{E}+05$ & $2.18 \mathrm{E}-02$ \\
\hline & 50 & $1.86 \mathrm{E}+05$ & $4.89 \mathrm{E}+01$ & $6.24 \mathrm{E}+05$ & $4.90 \mathrm{E}+01$ & $2.83 \mathrm{E}+05$ & $1.86 \mathrm{E}-02$ \\
\hline & 100 & $5.88 \mathrm{E}+05$ & $9.89 \mathrm{E}+01$ & $1.46 \mathrm{E}+06$ & $9.89 \mathrm{E}+01$ & $5.95 \mathrm{E}+05$ & 3.23E-02 \\
\hline
\end{tabular}

Table III. Comparison of ETLOBA with HS, IBA, ABC over Benchmark Functions

\begin{tabular}{|c|c|c|c|c|c|}
\hline \multirow{2}{*}{ Function } & \multirow{2}{*}{$\begin{array}{l}\text { Dim } \\
\text { (D) }\end{array}$} & HS & IBA & $\mathbf{A B C}$ & ETLOBA \\
\hline & & Mean (Std) & Mean (Std) & Mean (Std) & Mean (Std) \\
\hline \multirow{4}{*}{$f_{l}$} & 10 & $6.45 \mathrm{E}-08(3.07 \mathrm{E}-08)$ & $4.95 \mathrm{E}-17(2.30 \mathrm{E}-17)$ & 7.36E-17 (4.43E-17) & $1.95 E-98(4.37 E-98)$ \\
\hline & 30 & $7.21 \mathrm{E}+00(3.62 \mathrm{E}+00)$ & $2.92 \mathrm{E}-16(6.77 \mathrm{E}-17)$ & $4.69 \mathrm{E}-16(1.07 \mathrm{E}-16)$ & $1.36 \mathrm{E}-100(3.04 \mathrm{E}-100)$ \\
\hline & 50 & $5.46 \mathrm{E}+02(9.27 \mathrm{E}+01)$ & $5.39 \mathrm{E}-16(1.07 \mathrm{E}-16)$ & $1.19 \mathrm{E}-15(4.68 \mathrm{E}-16)$ & 9.53E-107 (2.13E-106) \\
\hline & 100 & $1.90 \mathrm{E}+04(1.78 \mathrm{E}+03)$ & $1.45 \mathrm{E}-15(1.63 \mathrm{E}-16)$ & $1.99 \mathrm{E}-06(2.26 \mathrm{E}-06)$ & 2.15E-96 (1.07E-095) \\
\hline \multirow{4}{*}{$f_{2}$} & 10 & $1.05 \mathrm{E}-05(5.23 \mathrm{E}-06)$ & $2.20 \mathrm{E}+01(7.46 \mathrm{E}+00)$ & $5.77 \mathrm{E}-17(2.98 \mathrm{E}-17)$ & $0.00 \mathrm{E}+00(0.00 \mathrm{E}+00)$ \\
\hline & 30 & $7.40 \mathrm{E}-01(7.00 \mathrm{E}-01)$ & $1.28 \mathrm{E}+02(2.49 \mathrm{E}+01)$ & $4.80 \mathrm{E}-05(2.43 \mathrm{E}-04)$ & $0.00 \mathrm{E}+00(0.00 \mathrm{E}+00)$ \\
\hline & 50 & $3.76 \mathrm{E}+01(4.87 \mathrm{E}+00)$ & $2.72 \mathrm{E}+02(3.27 \mathrm{E}+01)$ & 4.72E-01 (4.92E-01) & $0.00 E+00(0.00 E+00)$ \\
\hline & 100 & $3.15 \mathrm{E}+02(2.33 \mathrm{E}+01)$ & $6.49 \mathrm{E}+02(4.52 \mathrm{E}+01)$ & $1.46 \mathrm{E}+01(4.18 \mathrm{E}+00)$ & $0.00 E+00(0.00 E+00)$ \\
\hline \multirow{4}{*}{$f_{3}$} & 10 & $2.76 \mathrm{E}-04(7.58 \mathrm{E}-05)$ & $6.71 \mathrm{E}-02(3.61 \mathrm{E}-01)$ & $3.51 \mathrm{E}-16(6.13 \mathrm{E}-17)$ & $0.00 \mathrm{E}+00(0.00 \mathrm{E}+00)$ \\
\hline & 30 & 9.43E-01 (5.63E-01) & $1.75 \mathrm{E}+00(9.32 \mathrm{E}-01)$ & $3.86 \mathrm{E}-15(3.16 \mathrm{E}-15)$ & $0.00 E+00(0.00 E+00)$ \\
\hline & 50 & $5.28 \mathrm{E}+00(4.03 \mathrm{E}-01)$ & $8.43 \mathrm{E}+00(7.70 \mathrm{E}+00)$ & $4.38 \mathrm{E}-08(4.65 \mathrm{E}-08)$ & $0.00 \mathrm{E}+00(0.00 \mathrm{E}+00)$ \\
\hline & 100 & $1.32 \mathrm{E}+01(4.90 \mathrm{E}-01)$ & $1.89 \mathrm{E}+01(8.50 \mathrm{E}-01)$ & $1.32 \mathrm{E}-02(1.30 \mathrm{E}-02)$ & $0.00 E+00(0.00 E+00)$ \\
\hline \multirow{4}{*}{$f_{4}$} & 10 & $0.00 E+00(3.02 E-02)$ & $1.04 \mathrm{E}+00(1.13 \mathrm{E}+00)$ & $6.96 \mathrm{E}-17(4.06 \mathrm{E}-17)$ & $0.00 \mathrm{E}+00(0.00 \mathrm{E}+00)$ \\
\hline & 30 & $1.09 \mathrm{E}+00(3.92 \mathrm{E}-02)$ & $6.68 \mathrm{E}+00(6.43 \mathrm{E}+00)$ & $5.82 \mathrm{E}-06(3.13 \mathrm{E}-05)$ & $0.00 \mathrm{E}+00(0.00 \mathrm{E}+00)$ \\
\hline & 50 & $5.81 \mathrm{E}+00(9.16 \mathrm{E}-01)$ & $1.34 \mathrm{E}+02(2.41 \mathrm{E}+01)$ & $5.72 \mathrm{E}-01(9.22 \mathrm{E}-01)$ & $0.00 \mathrm{E}+00(0.00 \mathrm{E}+00)$ \\
\hline & 100 & $1.78 \mathrm{E}+02(1.98 \mathrm{E}+01)$ & $7.93 \mathrm{E}+02(7.96 \mathrm{E}+01)$ & $1.31 \mathrm{E}+01(6.30 \mathrm{E}+00)$ & $0.00 E+00(0.00 E+00)$ \\
\hline \multirow{4}{*}{$f_{5}$} & 10 & $6.52 \mathrm{E}+00(8.16 \mathrm{E}+00)$ & $1.10 \mathrm{E}+01(2.55 \mathrm{E}+01)$ & 4.62E-01 (5.44E-01) & $8.99 \mathrm{E}+00(\mathbf{8 . 4 E - 0 3})$ \\
\hline & 30 & $3.82 \mathrm{E}+02(5.29 \mathrm{E}+02)$ & $7.57 \mathrm{E}+01(1.16 \mathrm{E}+02)$ & 9.98E-01 (1.52E+00) & $2.89 \mathrm{E}+01(\mathbf{2 . 2 4 E}-\mathbf{0 2})$ \\
\hline & 50 & $2.47 \mathrm{E}+04(1.02 \mathrm{E}+04)$ & $6.30 \mathrm{E}+02(1.20 \mathrm{E}+03)$ & $4.33 \mathrm{E}+00(5.48 \mathrm{E}+00)$ & $4.90 \mathrm{E}+01(\mathbf{2 . 2 0 E}-\mathbf{0 2})$ \\
\hline & 100 & $1.5 \mathrm{E}+07(2.16 \mathrm{E}+06)$ & $6.42 \mathrm{E}+02(8.20 \mathrm{E}+02)$ & $1.12 \mathrm{E}+02(6.92 \mathrm{E}+01)$ & $9.90 \mathrm{E}+01(3.23 \mathrm{E}-02)$ \\
\hline
\end{tabular}




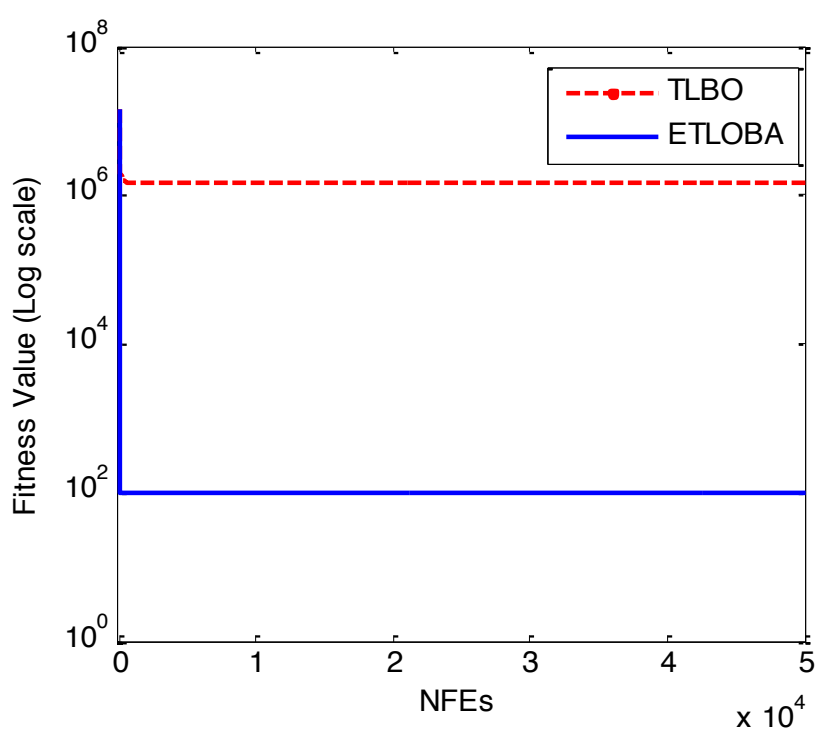

Fig. 7. Convergence of ETLOBA and TLBO for $F_{5}$ function (100-D)

\section{CONCLUSIONS}

Teaching-Learning Based Optimization with Opposition and elitism was formulated and its performance assessment was given for the 5-test functions on various dimensions ranging from 10-100. The presence of the two robust mechanisms had improved the convergence rate of traditional TLBO method and also had outperformed many different optimization based algorithms in terms of optimal values.

Future research may focus on extending ETLBOA for solving constrained optimization problems and modifying it suitably for multi-objective optimization problems as well.

\section{ACKNOWLEDGEMENTS}

This work was partially supported by the SGS in VSB Technical University of Ostrava, Czech Republic, under the grant No. SP2012/58, and was supported by the European Regional Development Fund in the IT4Innovations Centre of Excellence project (CZ.1.05/1.1.00/02.0070) and by the BioInspired Methods: research, development and knowledge transfer project, reg. no. CZ.1.07/2.3.00/20.0073 funded by Operational Programme Education for Competitiveness, cofinanced by ESF and state budget of the Czech Republic.

\section{REFERENCES}

[1] R.V. Rao, V.J. Savsani and D.P. Vakharia, "Teaching-Learning-Based Optimization: A novel optimization method for continuous non-linear large scale problems", Information Sciences, 183 (1)

[2] R. V. Rao, and V.J. Savsani, "Mechanical design optimization using advanced optimization techniques", Springer-Verlag, London.

[3] R.V. Rao, V.J. Savsani and D.P. Vakharia, “ Teaching-learning-based optimization: A novel method for constrained mechanical design optimization problems", Computer-Aided Design, 43(3), pp. 303-315.

[4] R.V. Rao and V.K. Patel, "Multi-objective optimizationof combined Brayton add reverse Brayton cycles using advacned optimization algorithms. Engineering Optimization, 2012, doi: 10.1080/030515X.2011.624183.

[5] R.V. Rao and V.Patel, "An elitist teaching learning based optimization algorithm for solving complex constrained optimization problems", International Journal of Industrial Engineering Computations, doi: 10.5267/jiijiec.2012.03.00.

[6] D. Karaboga, B.Akay, "Artificial Bee Colony (ABC), harmony search and bees algorithms onf Numerical Optimization", Proceedings of IPROMS-2009, Cardiff, UK, 2009.

[7] H.R. Tizoosh, "Opposition-based learning, A new scheme for machine intelligence," In Proc. Int. Conf. Comput, Intell, Modeling Controland Autom, Vienna, Austria, 2005, vol. 1, pp, 695-701.

[8] M. Shokri, H.R. Tizhoosh, M.Kamel, "Opposition-based $Q(\lambda)$ algorithm" In Proc. IEEE World Congress on Comput, Intell, Vancouver, BC, Canada, 2006, pp. 646-653. 